\title{
Time-intensity equivalence in auditory lateralization: A graphical method'
}

\author{
Charles S. Watson and Brant T. Mittler 2 \\ UNIVERSITY OF TEXAS
}

\begin{abstract}
Abstraet
A graphical response was used to establish equivalent binaural time- and intensity-differences in auditory lateralization. For intensity differences less than about $4.5 \mathrm{db}$ a constant equivalence of approximately $60 \mu \mathrm{sec}$. per $\mathrm{db}$ is found, for $500 \mathrm{cps}$ tonal pulses. For larger intensity differences more time per $\mathrm{db}$ is required.
\end{abstract}

\section{Problem}

Primary cues in the auditory localization of tones are differences in binaural (dichotic) intensity, probably the only cue at high frequencies, and differences in dichotic time or phase, the major cue at low frequencies. Both dichotic-time- and dichotic-level-differences can shift a sound image away from the median plane for frequencies in the vicinity of $500 \mathrm{cps}$. The relative contributions of these two cues have most often been studied through balancing the effect of one against that of the other in order to bring an image to subjective center. Dichotic time and dichotic level are most easily varied independently by delivering the sounds over earphones. This results in the sound's being reported at a place in the head (lateralized) rather than in the space around it (localized). Moushegian \& Jeffress (1959) have described several methods of studying the effects of dichotic stimulation and the results obtained with each method.

A statistic expressing the relative contribution of time and intensity when these cues are balanced in opposition to each other is the time-intensity trading ratio, defined as the number of microseconds ( $\mu \mathrm{sec}$.$) of$ dichotic delay required to offset one decibel (db) of dichotic intensity difference. Values of this trading ratio have been reported ranging from 2.0 (Shaxby \& Gage, 1932) to 150 (Christman \& Victor, 1955) $\mu$ sec. per db. Smaller values are generally found for lower frequencies and louder sounds, larger ones for high frequencies, impulsive sounds (clicks) and weaker sounds. Perfectly consistent results, however, are still lacking, perhaps due to the variety of methods used in establishing "equivalent" dichotic time and intensity conditions. Although most studies have used combinations of time and intensity cues, Teas (1962) has devised a method of assessing the effects of these variables singly. His Ss manipulated the dichotic time delay of clicks and traced the resulting lateralization with pencil and paper. A somewhat similar method is introduced here, and its use is demonstrated in studying the effects of both intensity differences and time differences. An additional modification is introduced in that the delay or intensity decrement is permuted from one ear to the other for successive pulses, thus tracing out a subjective distance rather than a single lateralized point. The results are used to describe equivalent time- and intensity-differences for images displaced varying distances from subjective center, as opposed to many of the earlier studies in which equivalence was discussed only in the case of the centered image.

\section{Subjeets}

The Ss were three experimentally naive male students, 16 and 17 years old, and the second author, also 17. All Ss' audiograms were well within clinically-defined normal limits.

\section{Apparatus}

The apparatus was that typically used in lateralization research: an oscillator, an electronic switch, a variable delay line, a one-db step attenuator and a pair of earphones (TDH-39). The electronic switch was adjusted to reverse (permute) tone-pulses to the earphones so that a delay or reduction in level was introduced to one phone on one pulse and to the other phone on the succeeding pulse. All pulses were of a $500 \mathrm{cps}$ pure tone, 1/2 sec. in duration, $65 \mathrm{db}$ re 0.0002 microbar and having a rise-decay time of $25 \mu \mathrm{sec}$. The interpulse time was $1 / 2$ sec. The response "apparatus" was a pencil and a sheet of horizontally lined paper (8-1/2 by 11 in). Three vertical lines, at center and $9 \mathrm{~cm}$ to either side, were labeled "center," "left ear" and "right ear." A sheet of cardboard served as a mask, through which one of the horizontal lines could be seen at a time. The Ss were seated in a quiet room.

\section{Procedure}

The naive Ss were told only that they would be listening to sounds that might seem to move about in their heads and that they should trace the magnitude of this movement by drawing a line between the "ears" on the sheet of paper. After an initial training period of approximately $10 \mathrm{~min}$. with a variety of binaural and monaural conditions each $\mathrm{S}$ was run for 27 daily experimental sessions, making 20 judgments in each session. Half of the sessions involved level differences, the other half, time differences. Time- and level-sessions were scheduled in random order, as were the conditions on each trial within a session. The level differences were $0,2,4,6,8,10$, and $12 \mathrm{db}$, the time differences 0,90 , 180,270 , and $360 \mu \mathrm{sec}$. (Because of the truly random sequencing, the total number of trials per condition varied from 43 to 57.) The length of each trial depended on the time required to make the judgment, the average was kept at about 13 sec. by hurrying the Ss when they 
tended to take longer times. The $\mathrm{S}$ indicated both when he had made a judgment and when he was ready for the next series of pulses.

Results and Discussion

The mean lengths of lines drawn under each of the intensity conditions are shown in Fig. 1A. Movement of the sound image is a nearly linear function of dichotic intensity-difference from 0 to about $4.5 \mathrm{db}$, while larger differences in intensity have a decreasing incremental effect on the sound image. This bending-over is similar to that found by Teas for time differences greater than about $450 \mu \mathrm{sec}$. Figure 1B shows that the bending-over is also characteristic of our results for time differences. A linear portion of the time functions runs from 0 to $270 \mu$ sec., where it begins to bend, again for all Ss. Figure 2 illustrates those conditions that yield equal subjective movements of the sound image. The mean curves from the first figure are shown here with the abscissas adjusted to make the linear portions of the functions coincident. Throughout these linear portions approximately $60 \mu \mathrm{sec}$. of interaural time delay can be seen to be the subjective equivalent of one $\mathrm{db}$ of intensity difference. Since the time function bends more abruptly than the intensity function, the amount of time difference equivalent to one $\mathrm{db}$ increased above $4.5 \mathrm{db}$. This is consistent with Teas' data, in which the sound image actually moves back toward the center of the head when dichotic time differences are increased beyond about $450 \mu \mathrm{sec}$.
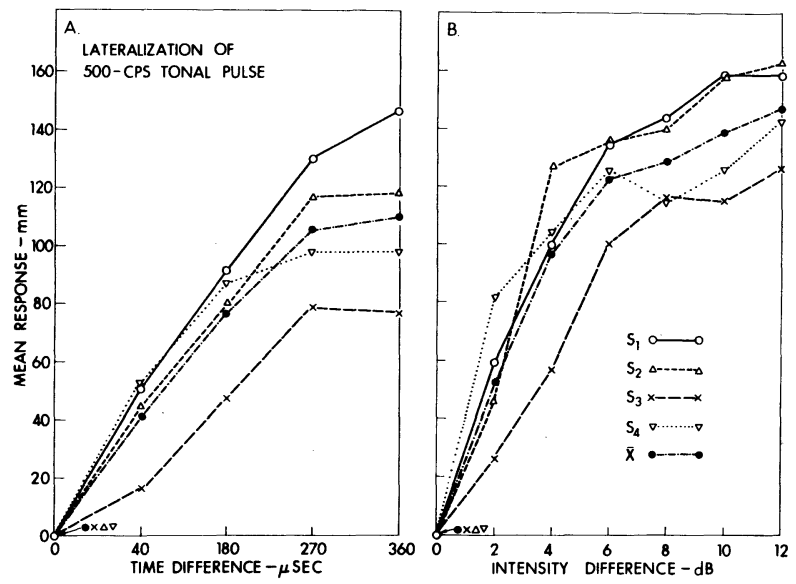

BINAURAL CONDITIONS

Fig. 1. Averages of lateralization-responses to binaural intensity differences and to binaural time differences. Listeners responded by drawing a line to indicate the locus of a sound image. Time- and intensity-increments were permuted from ear-to-ear, producing a sound which was perceived as moving back-and-forth across the median plane.

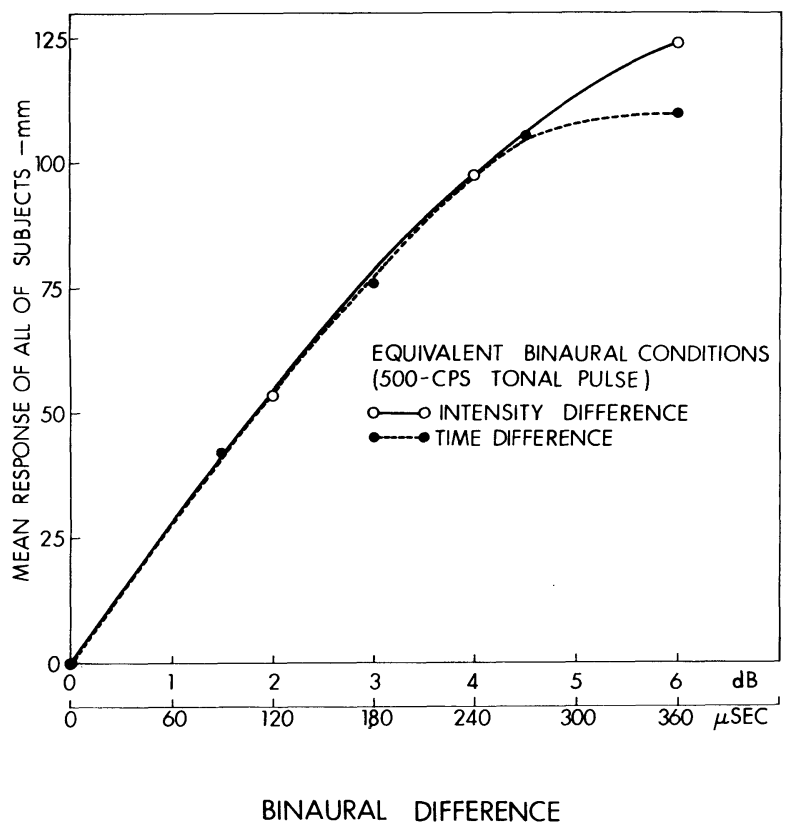

Fig. 2. Equivalent binaural time- and intensity-differences, plotted by adjusting the abscissas to make the two functions coincident. This adjustment emphasizes the similarity in subjective effect of $60 \mu$ sec. and $1.0 \mathrm{db}$ in shifting a sound image off of the median plane.

This method of equal subjective judgments was apparently learned by naive listeners with considerably greater ease than methods requiring verbal descriptions of the lateralized place of a sound image. While we would hesitate to place great reliance on the particular size of a subjective response like the one used here, we believe that considerable importance may be attached when independent stimulus conditions produce the same response, whatever that response may be.

\section{References}

CHRISTMAN, R. J., \& VICTOR, G. The perception of direction as a function of binaural temporal and amplitude disparity. Rome Air Development Center, ARDC, USAF, Rome, New York: Tech. Note RADC TN-55-302, 1955, 1-23.

MOUSHEGIAN, G., \& JEFFRESS, L. A. Role of interaural time and intensity differences in the lateralization of low-frequency tones: J. Acoust. Soc. Amer., 1959, 31, 1441-1445.

SHAXBY, J. H., \& GAGE, F. H. The localization of sounds in the median plane. Med. Res. Council, Brit., Spec. Rep. No. 166, 1932, 1-32.

TEAS, D. C. Lateralization of acoustic transients. J. Acoust. Soc. Amer., 1962, 34, 1460-1465.

\section{Notes}

1. The authors are grateful to Professor Lloyd A. Jeffress for his wise counsel throughout all phases of this experiment. The research was supported under a grant from the National Aeronautics and Space Administration R-129 through ONR Contract Nonr 3579(04).

2. The junior author conducted this research while working in a Summer Science-Participation Conference for High-Ability High School Students conducted at The University of Texas, under the sponsorship of the National Science Foundation. 